\title{
Resentimiento y Psiquismo (Primera Parte)
}

\author{
Klaus Droste* \\ Centro de Estudios Tomistas \\ Universidad Santo Tomás de Chile
}

\section{Introducción}

El tema del resentimiento no es un tema común en psicología. En el ámbito de los problemas psíquicos no es el resentimiento un elemento considerado con frecuencia como causa de malestar y dolor en una persona. Cuando se está con alguien que manifiesta tener dificultades en algunas áreas de su vida; vivir una vida triste, amarga, con alteraciones importantes, incapacidad de disfrutar las cosas que debieran ser fuente de gozo y alegría, no es el resentimiento un concepto conocido como para ayudar a explicar lo que sucede. El concepto de resentimiento que buscamos precisar es de útil conocimiento para cualquier psicólogo. Es un concepto que puede ayudar a conocer mejor al hombre y su psicología, y permite explicar algunos fenómenos interesantes que se dan en la vida de algunas personas.

"El resentimiento puede hacernos comprensible, tanto grandes procesos del conjunto en la historia de las concepciones morales, como sucesos que presenciamos en la pequeña vida diaria"1 .

\section{Definición del concepto de resenti- miento}

Para formar una idea acerca del resentimiento y sus diferentes manifestaciones en la vida humana, es necesario comenzar por definirlo. Hay que advertir que al estudiarlo es fácil comenzar a ver resentimiento donde no lo hay. No es difícil confundirse y realizar apreciaciones que son del todo equívocas. Por lo general, determinar con claridad si ciertos comportamientos, actitudes, valores e ideales son fruto del resentimiento, no es algo sencillo.

¿Qué es el resentimiento?

Max Scheler define el concepto del modo siguiente:

\footnotetext{
* Coordinador investigación y extensión, Centro de estudios Tomistas.

${ }^{1}$ Max Scheler, El resentimiento en la moral, p. 69.
}

"Se trata de una determinada reacción emocional frente a otro, reacción que sobrevive y revive repetidamente, con lo cual penetra cada vez más en el centro de la personalidad, al par que se va alejando de la zona expresiva y activa de la persona"2.

En primer lugar el resentimiento se reconoce como una reacción emocional frente a otro; es decir, otra persona. En un ejemplo, puede ser que yo llegue al trabajo y al cruzar el umbral de la puerta, alguien ríe burlonamente por un problema congénito en mi nariz. Por problema congénito se quiere significar sencillamente que esta nariz es fea. Producto de ello me acerque a la persona y manifieste abiertamente mi molestia. Qué ha sucedido: se burló de mí, me sentí herido y me defendí enfrentándolo. Esta reacción emocional no da lugar a resentimiento.

Por otra parte, puede ser que alguien ría burlonamente de mi nariz uno y otro día y, esto me humille, no diga nada y esta reacción emocional escondida la lleve conmigo y sobreviva y reviva en mí de manera repetida, y en mi interioridad se mantenga expuesta.

Claramente la reacción emocional es de carácter negativo, lo dice el autor: "la palabra implica que la cualidad de esta emoción es negati$\mathrm{va}^{\text {"3. }}$. Esta emoción que sirve al resentimiento se mantiene viva, y a medida que "sobrevive y revive", como indica Scheler, va penetrando cada vez más en uno, calando hondamente en lo profundo de la personalidad. No obstante, que cada vez lo demuestro menos, cada vez es más íntima y el dolor que causa cada vez es menos notorio.

Max Scheler también describe el resentimiento de un modo más plástico y dice:

"El resentimiento es una autointoxicación psíquica, con causas y consecuencias bien definidas. Es una actitud psíquica permanente, que surge al

\footnotetext{
${ }^{2}$ Max Scheler, El resentimiento en la moral, p. 12.

${ }^{3}$ Max Scheler, El resentimiento en la moral, p. 14.
} 
reprimir sistemáticamente la descarga de ciertas emociones y afectos, los cuales son en sí normales y pertenecen al fondo de naturaleza humana; tiene por consecuencia ciertas propensiones permanentes a determinadas clases de engaños valorativos y juicios de valor correspondientes"

La denomina "autointoxicación psíquica"; quiere decir que envenena al hombre en el cual se produce. Va penetrando los diversos ámbitos de la personalidad y va provocando una suerte de "emponzoñamiento psicológico". Es interesante considerar lo que provoca la intoxicación a nivel físico. Esta se manifiesta como un colapso del sistema. Ello impide el adecuado funcionamiento de la totalidad. A medida que progresa va abarcándolo todo, de modo que, finalmente, se transforma en una septicemia generalizada que lleva a la muerte. Septicemia significa que "corrompe la sangre, es una enfermedad que pertenece al género de las infecciones graves, producidas por el paso a la sangre y su multiplicación en ella de diversos gérmenes patógenos procedentes de las supuraciones con síntomas de extensa intoxicación"s. El autor ha llamado al resentimiento "autointoxicación psíquica".

Otros autores llaman al resentimiento "veneno psicológico", "veneno activísimo, sutil e invisible" , "es ira ulcerada, a veces mezclada de envidia y aninda mais de soberbia, encima a veces de pereza", "es como una herida enconada y después gangrenosa"8.

Para que se dé resentimiento advierte el autor del "Resentimiento en la moral" que, no sólo debe darse la emoción negativa frente a otro, sino que junto con ello, se experimenta impotencia, y para precisar lo distingue de venganza.

"Dos caracteres son esenciales para la venganza: un refrenamiento y detención momentáneos al menos (o durante un tiempo determinado), del contraimpulso inmediato (y de los movimientos de cólera y furor enlazados con él) y un aplazamiento de la contrarreacción para otro momento y situación más apropiada ("aguarda, que otra vez será")"'.

\footnotetext{
${ }^{4}$ Max Scheler, El resentimiento en la moral, p.17.

${ }^{5}$ Real academia Española, diccionario de la lengua española, vigésima primera edición.

${ }^{6}$ Leonardo Castellani, Psicología Humana, Cáp. VI. Pág. 156.

${ }^{7}$ Ibíd.

${ }^{8}$ Ibíd.

${ }^{9}$ Max Scheler, El resentimiento en la moral, p. 18.
}

\section{Resentimiento y venganza}

Empero, entre venganza y resentimiento, según lo expuesto por el autor, se aprecia cierta relación.

"La condición necesaria para que surja el resentimiento se da tan sólo allí donde una especial vehemencia de estos afectos, propios de la sed de venganza, va acompañada por el sentimiento de la impotencia para traducirlos en actividad; y entonces se enconan, ya sea por debilidad corporal o espiritual, ya por temor y pánico a aquel a quien se refieren dichas emociones"10. Existe un sentimiento de impotencia radical, que impide reaccionar en defensa de la propia estima. Es la sensación de que "no hay nada que hacer", "mejor será callar", "mejor acatar", "más vale obedecer", "mejor someterse". Lo que sucede en el caso del resentimiento, no se debe confundir con las imágenes que nos formamos, muchas veces, con relación a ciertas actitudes que observamos, pues en muchísimas ocasiones, no se hace nada, se calla, se acata y obedece, por un acto libre que surge de la comprensión honda que se tiene de la realidad y por lo tanto, no hay resentimiento sino gozo profundo.

Pero puede suceder que, por algo que se ha dicho o hecho, nos sintamos heridos en lo que somos y experimentemos cierta impotencia frente al otro, que nos provoque una herida, "que sobreviva y reviva repetidamente, que vaya penetrando cada vez más en lo profundo de la personalidad, al tiempo que se va alejando de la zona activa y expresiva de la persona", como ha dicho el autor.

Así, pues, "la sed de venganza conduce al resentimiento tanto más reprimida quede la ejecución de la venganza, que restablece el sentimiento del propio valer ofendido o del honor ofendido, o de satisfacción del daño sufrido; y en medida mayor aun, cuanto más reprimida sea también la expresión imaginaria, interna, y, finalmente, sofocado el movimiento mismo de la venganza"11.

Sólo en estas circunstancias se agrega a este estado la tendencia a restar valor al valer ajeno, resolviendo la tensión generada mediante falso examen de la realidad ${ }^{12}$. Anteriormente, el autor ha hablado ya de "engaños valorativos"13.

\footnotetext{
${ }^{10}$ Max Scheler, El resentimiento en la moral, p. 22.

${ }^{11}$ Max Scheler, El resentimiento en la moral, p. 24.

12 "Sólo entonces se añade a este estado la tendencia a la detracción del valor ajeno, mediante la cual, la tensión se resuelve por un examen ilusorio". Max Scheler, El resentimiento en la moral, p. 24.

${ }^{13}$ Max Scheler, El resentimiento en la moral, p.17.
} 
Esto porque existe un aspecto fundamental que el autor quiere destacar; es que el resentimiento es falsificador de valores. Sucede así, dado que el resentimiento resuelve la tensión, como ya hemos dicho, mediante un examen ilusorio de lo real.

Para entenderlo es útil observar lo que en ocasiones sucede en nuestro psiquismo, según lo describe el autor, y que no es aún propiamente resentimiento. Se da cuando existen fuertes deseos de conseguir algo y, al mismo tiempo, se experimenta la incapacidad para poder realizarlo. Nace entonces en la conciencia un modo para resolver el problema entre el querer y el no poder, reduciendo, rebajando, aminorando o negando el valor de aquello que deseamos o apeteciendo algo contrario.

El propio autor lo expresa del modo siguiente: "Cuando se sienten fuertes afanes de realizar un valor y, simultáneamente, la impotencia de cumplir voluntariamente estos deseos, por ejemplo, de lograr un bien, surge una tendencia de la conciencia a resolver el inquietante conflicto entre el querer y el no poder, rebajando, negando el valor positivo del bien correspondiente, y aun, en ocasiones, considerando como valioso un contrario cualquiera de dicho bien. Es la historia de la zorra y de las uvas verdes". ${ }^{14}$

Agrega: "Cuando hemos luchado en vano por el amor y la consideración de una persona, descubrimos fácilmente nuevas cualidades negativas en ella, o "nos conformamos" y "nos consolamos", diciéndonos que con la cosa a que tiende nuestro deseo "no se consigue tanto", que la cosa no posee esos valores, o no los posee en la medida que creíamos"15.

"Se trata, en primer término, tan sólo de la afirmación, verbalmente formulada, de que alguna cosa, un determinado bien, o una persona, o un estado, en sumo, la cosa concreta deseada, no posee el valor positivo que tanto incitó nuestro deseo; por ejemplo, que la persona cuya amistad habíamos ansiado tener, no es tan "honrada", o "valiente", o "lista"; que las uvas no saben tan bien, que están, quizá, verdes"16.

El autor hace mención en este fragmento a la fábula de Esopo "La zorra y las uvas". Ésta narra que "una zorra hambrienta, como viera unos racimos colgar de una parra, quiso apoderarse de

\footnotetext{
${ }^{14}$ Max Scheler, El resentimiento en la moral, p. 69

${ }^{15} \mathrm{Max}$ Scheler, El resentimiento en la moral, p. 70.

${ }^{16}$ Ibíd.
}

ellos y no pudo. Marchándose, dijo para sí: “Están verdes"17.

La moraleja reza: “Así, también algunos hombres inhábiles por su incapacidad para lograr lo que quieren echan la culpa a las circunstancias", ${ }^{18}$

Este tipo de caso no es todavía resentimiento, esto no es una falsificación de valores, porque se reconoce aún el valor objetivo de aquello que contrista.

"Con esta tendencia a la detracción del objeto, se resuelve el conflicto entre la intensidad del apetito y la impotencia; y el dolor, unido a ella, baja entonces de grado. Nuestro apetito o su intensidad nos parece ahora "inmotivado" ya que la cosa "no era tan valiosa"; se debilita, gracias a esto, y, merced a esta debilitación, disminuye la magnitud del conflicto entre él y la impotencia; de modo que el sentimiento de nuestra vida y poder asciende de nuevo algunos grados, aunque sobre una base ilusoria"19.

\section{Resentimiento y envidia}

Así como el autor ha distinguido resentimiento de venganza, es interesante, también, distinguir también el resentimiento, como actitud psíquica, de la envidia, como pasión del alma, para clarificar más profundamente el concepto que nos interesa.

Por envidia entendemos "tristeza de los bienes ajenos" ${ }^{\text {"20 }}$ por cuanto un bien de otro es tomado como mal propio.

Esto se da de dos modos, afirma Santo Tomás de Aquino. El primero, que no es propiamente envidia, cuando nos entristecemos del bien de otro que nos pone en riesgo de sufrir algún perjuicio. Esta tristeza es efecto del temor. En segundo lugar cuando "el bien de otro se considera como mal personal porque aminora la propia gloria o excelencia. De esta manera siente la envidia tristeza del bien ajeno, y por eso principalmente envidian los hombres aquellos bienes que reportan gloria y con los que los hombres desean ser honrados y tener fama, como enseña el Filósofo"21.

\footnotetext{
${ }^{17}$ Esopo, Fábulas y vida de Esopo, Gredo, Pág. 20.

18 Ibíd.

${ }^{19}$ Max Scheler, El resentimiento en la moral, p. 71.

${ }^{20}$ Santo Tomás de Aquino, Suma de Teología, I-II. Q.35. a. 8. obj. 3.

${ }^{21}$ Santo Tomás de Aquino, Suma de Teología, II-II. Q.36. a.1.
} 
El concepto de envidia se puede precisar aún más. Lo que permite comprender bajo qué condiciones ésta se da y cómo puede afectar la vida y la convivencia con aquellos que se encuentran más cerca de nosotros. La envidia puede experimentarla el hombre desde muy pequeño, asunto que constata muy gráficamente San Agustín en las confesiones ${ }^{22}$; también se encuentra muy bien retratada en la literatura universal, con toda su profundidad cuando es padecida por alguien: "una envidia abrasadora que oprime y contrae todo su ser"23.

Solamente se da envidia "de aquellos con los que el hombre quiere o igualarse o aventajarles en su gloria"24. Es por eso que es frecuente la envidia "de quienes se encuentran cerca y con quienes se esfuerza por igualarse $o$ aventajar"25. Es por eso que el hecho que ellos sobresalgan en algo, queriendo aventajarlos nosotros, "cede en perjuicio de nuestros intereses, y por eso se origina la tristeza"26. San Agustín lo constata así en sus Confesiones; nos dice: “¿Qué hacía el que me azotaba sino lo mismo que yo? Si era vencido por un colega suyo en un asuntillo sin importancia, se encolerizaba o se llenaba de envidia"27.

Es una experiencia cotidiana el que sólo nos empeñamos por alcanzar aquello que nos parece accesible. "Nadie, en efecto, si no es un demente, pretende igualarse ni aventajar en gloria a quienes son muy superiores a él"28. Si alguien, por ejemplo, se destaca en algo a lo cual nosotros no aspiramos por considerarlo muy por encima de nuestras capacidades, no le envidiamos. "La diferencia está cuando la diferencia es pe-

\footnotetext{
22 "Una vez vi y observé a un niño envidioso. Todavía no hablaba, y ya miraba pálido y con cara amargada a otro niño que mamaba a la vez que él. ¿Quién no ha observado esto? Dicen que las madres y las nodrizas saben cómo desterrar estas inclinaciones de los niños. Y llamamos inocentes a los niños..., yo no sé cómo puede llamarse inocencia a no soportar como hermano de leche, que mama copiosa y abundantemente, al que está necesitado del mismo alimento y qué con él sostiene su vida". San Agustín, Las Confesiones. Ediciones palabra. 1998. Madrid. Pág. 14.

${ }^{23}$ Vladimir Soloviev, Los tres diálogos y el relato del Anticristo, XX, Pág. 165.

${ }^{24}$ Santo Tomás de Aquino, Suma de Teologia, II-II, q.36. a.1. ad. 2 .

${ }^{25}$ Ibíd.

${ }^{26}$ Ibíd.

${ }^{27}$ San Agustín, Las Confesiones, Pág. 19.

${ }^{28}$ Santo Tomás de Aquino, Suma de Teología, II-II, q.36. a.1. ad. 2 .
}

queña, y otro sobresale en algo en que nosotros también podríamos. Eso nos entristece"29.

En la envidia se da un proceso distinto al del Resentimiento. El envidioso, a diferencia del resentido, en un principio busca disminuir la gloria ajena, lo que puede darse de manera oculta, y es lo que se llama murmuración, o bien públicamente, lo que conocemos como difamación. Ahora bien, si tiene como algo posible el disminuir la gloria ajena, se da la alegría en la adversidad, porque el envidioso tiene la esperanza del futuro desprestigio del vecino. Puede suceder lo contrario, esto es que no se vea como posible lograr disminuir la gloria ajena y ahí viene la aflicción en la prosperidad, es decir, aun estando bien, sufro porque el otro está mejor que yo, a pesar de mis esfuerzos porque no lo esté ${ }^{30}$.

\footnotetext{
29 "Nadie pone empeño en conseguir lo que está muy por encima de él. De ahí que, cuando alguien logra sobresalir en ello, no le envidia. Pero si la diferencia es poca, le parece que puede conseguirlo. Por eso, si fracasa en su intento, por el exceso de gloria del otro se entristece, y ésa es la razón por la que, quienes ambicionan honores, son más envidiosos. Lo son igualmente los pusilánimes, porque todo lo planean a lo grande, y con el menor bien conseguido por otros se consideran ellos enormemente defraudados. Por eso leemos en Job 5,2: Al apocado le mata la envidia. Y San Gregorio, por su parte, escribe en V Moral.: No podemos envidiar sino a quienes tenemos por mejores que nosotros en algo". Santo Tomás de Aquino, Suma de Teología, II-II, q.36. a.1. ad. 3.

30 "En el proceso de la envidia hay un principio, un medio $\mathrm{y}$ un fin. Al principio, en efecto, hay un esfuerzo por disminuir la gloria ajena, bien sea ocultamente, y esto da lugar a la murmuración, bien sea a las claras, y esto produce la difamación. Luego quien tiene el proyecto de disminuir la gloria ajena, o puede lograrlo, y entonces se da la alegría en la adversidad, o no puede, y en ese caso se produce la aflicción en la prosperidad. El final se remata con el odio, pues así como el bien deleitable causa el amor, la tristeza causa el odio, según hemos demostrado (q.34. a.6.). Ahora bien, la aflicción en la prosperidad del prójimo, en cierto modo, se identifica con la envidia, como es el caso de que la prosperidad que da lugar a la tristeza, constituye precisamente la gloria que tiene el prójimo. Pero en otro sentido es hija de la envidia, y es el caso de que esa prosperidad la tiene el prójimo a despecho de los esfuerzos del envidioso para impedirlo. Mas la satisfacción de ver al prójimo en dificultad no se identifica directamente con la envidia, sino que se sigue de ella, ya que de la tristeza provocada por el bien del prójimo, es decir, la envidia, se sigue la satisfacción de ver el mal que le ha ocurrido". Santo Tomás de Aquino, Suma de Teologia, II-II, q.36. a.4. ad. 3.
} 